\title{
CONSELHOS TUTELARES E PSICOLOGIA: POLÍTICAS PÚBLICAS E PROMOÇÃO DE SAÚDE
}

\author{
Vânia Conselheiro Sequeira* \\ Manuela Monti \\ Fernando Marques Oliveira Braconnot
}

\begin{abstract}
RESUMO. Este artigo busca refletir sobre o papel do conselho tutelar na sociedade a partir de uma experiência de estágio curricular em Psicologia Jurídica nos cursos de graduação em Psicologia no Brasil. As atividades do estágio foram observações do cotidiano de um Conselho Tutelat (CT), plantão de Psicologia Jurídica junto à população e discussão dos casos atendidos com conselheiros e a coordenação de um grupo de adolescentes encaminhados por uma escola da região do Estudo. Este artigo pretende mostrar que o conselho tutelar é uma instituição que denuncia os conflitos subjacentes em uma sociedade excludente; além disso, o trabalho aponta caminhos para que esse órgão possa funcionar como um aparato de promoção de saúde.
\end{abstract}

Palavras-chave: Conselho Tutelar; políticas públicas; promoção de saúde.

\section{CHILD PROTECTION AGENCY: A REFLECTION ON PUBLIC POLITICS AND HEALTH PROMOTION}

\begin{abstract}
This article tries to reflect about the role of the Child Protection Agency in society, starting from a curricular internship experience in Legal Psychology on the graduation course of Psychology in Brazil. The activities of the internship were: observation on the daily activities of the institution, legal psychological care of the population, discussion with advisors of the attended cases and coordination of a group with adolescents who were sent to a nearby school. This article intends to depict that the Child Protection Agency is an institution that denounces the conflicts underlying an excluding society; moreover, this work points out ways so that this organization could work as an apparatus for the promotion of health.
\end{abstract}

Key words: Child Protection Agency; public politics; promotion of health.

\section{CONSEJO TUTELAR Y PSICOLOGIA: POLÍTICAS PÚBLICAS Y PROMOCIÓN DE SALUD}

RESUMEN. Este artículo busca reflexionar sobre el papel del Consejo Tutelar en la sociedad, a partir de una experiencia del aprendizaje curricular en Psicología Jurídica en el curso de grado de Psicología en Brasil. Las actividades del aprendizaje fueron: observaciones del cotidiano de la institución, turnos de Psicología Jurídica a la populación, discusiones de los casos atendidos con consejeros y coordinación de un grupo con adolescentes encaminados por una escuela de la región. Este artículo pretende mostrar que el Consejo Tutelar es una institución que denuncia los conflictos subyacentes de una sociedad excluyente; además de eso, el trabajo apunta caminos para que este órgano pueda funcionar como un aparato de promoción de salud.

Palabras-clave: Consejo tutelar; políticas públicas; promoción de salud.

Psicóloga. Doutora em Ciência Sociais pela PUC/SP. Professora e Supervisora em Psicologia Jurídica Universidade Presbiteriana Mackenzie, São Paulo.

\# Psicologa formada pela Universidade Presbiteriana Mackenzie. Mestranda em Psicologia Escolar e do Desenvolvimento Humano pela USP/SP.

II Psicólogo e aluno da pós-graduação pela Universidade Presbiteriana Mackenzie. 
Tendo em vista que o papel do conselho tutelar é promover uma política de direitos e sensibilizar o Estado e a sociedade a atenderem a esses direitos, defendendo as pessoas cujos direitos sejam violados ou ameaçados (Souza Neto, 2006), o presente artigo tem como objetivo refletir sobre esse órgão, seu papel social, suas práticas de atendimento e suas demandas, que englobam desde a solicitação de vagas na escola até questões mais complexas e de alto grau de vulnerabilidade social, relacionadas à não garantia dos direitos básicos da população, como moradia, saúde, educação, alimentação.

Foi no período colonial, segundo Souza Neto (2006), que tiveram início as práticas de atendimento aos pobres, mas somente no século XX a pobreza passou a ser entendida no Brasil como uma questão social. Após 1930 foi criado o Departamento de Assistência Social e os trabalhos filantrópicos passaram a ser normatizados pelo Estado. Neste contexto, "as práticas de atendimentos à criança e ao adolescente mais reforçavam os processos de marginalização e de exclusão social do que de cidadania" (Souza Neto, 2006, p. 185). Em 1942 instituiu-se o Serviço de Assistência do Menor (SAM). Este foi extinto em 1964 e a intervenção pública junto às crianças e adolescentes passou a ser exercida por meio da Política do Bem-Estar do Menor (PNBEM). Com o processo de abertura política do País, a PNBEM sofreu críticas, tornando-se visível a eficiência do Estado na produção de menores de rua, menores em situação de risco, como consequência de políticas de exclusão social. Com diversos avanços nas políticas públicas, foi criado o Código do Menor de 1979 e, após a promulgação da Constituição Federal de 1988, o Estatuto da Criança e do Adolescente (ECA) (Cruz, Hillesheim, Guareschi \& 2005).

Atualmente existem mais de 27 mil conselhos distribuídos em mais de 5.500 municípios (Souza Neto, 2006). De acordo com o ECA, (Brasil, 1990, art. 132) cada cidade deve ter pelo menos um Conselho Tutelar (CT), o qual é formado por cinco conselheiros eleitos pela população. Os conselhos tutelares devem funcionar de forma autônoma e têm como função receber e acolher denúncias de situações que violem as prescrições do ECA, assim como orientar e encaminhar casos para os órgão jurídicos competentes. Neste sentido, é possível ainda pensar no Conselho Tutelar como instrumento de prevenção, pois, segundo Araújo e Mattioli (2004), existem muitos casos que podem ser solucionados no próprio $\mathrm{CT}$, principalmente aqueles em que possa vir a ocorrer violência.
A criação dos Conselhos de Direitos da Criança e Adolescentes e dos Conselhos Tutelares tem por base uma política de defesa de direitos, mas o desempenho destes conselhos ainda depende de equipamentos sociais adequados, algo ainda escasso no País (Rizzini, Barker, Cassaniga \& 2000). Ainda que o ECA aponte para políticas sociais básicas e programas de apoio ao desenvolvimento integral, na realidade, o Brasil continua a oferecer serviços de baixa qualidade, de caráter assistencial e emergencial.

Os Conselhos "têm o papel de aglutinar forças para reverter a dinâmica das políticas sociais que funcionam mais como reprodutoras da desigualdade" (Souza Neto, 2006, p. 187). Não obstante, o fato de serem espaços públicos não significa que resolverão todos os problemas de democratização ou que impedirão a violação de direitos. Souza Neto (2006) afirma que os Conselhos devem buscar uma dinâmica criadora, podendo ser compreendidos como instrumentos de conquista da implantação de novos programas sociais que respondam às necessidades efetivas da população. A rede deve ter em vista a proteção da criança, do adolescente e da família e promover um conjunto de ações justapostas e articuladas que abranja as políticas, a formação da subjetividade e as relações intersubjetivas. Tais ações "devem contribuir para que o sujeito seja capaz de lutar pelos ideários pessoais e da humanidade, de sustentar o patamar de cidadão e de refletir sobre sua história como estratégia para evitar que se instaurem projetos de dominação" (Souza Neto, 2006, p. 195).

As ações preventivas no Brasil ainda são limitadas, assim como as ações que tenham como foco a promoção de saúde (Rizzini et al., 2000). Valadão (2003) considera que a promoção da saúde envolve a ação sobre as causas, os "determinantes de saúde", ou seja, as "condições e recursos considerados essenciais para a saúde: paz, habitação, educação, alimentação, renda, ecossistema estável, recursos sustentáveis, justiça social e equidade" (p.204). Rizzini et al. (2000) ressaltam que o enfoque na prevenção não basta, pois ao falarmos de prevenção, o que se tem em mente são os problemas e riscos a serem evitados, em vez invés da melhoria das possibilidades e competências dos indivíduos. Neste sentido, o enfoque sobre a promoção de saúde seria mais efetivo se tivesse em vista "as possibilidades e os potenciais existentes para a promoção de um desenvolvimento saudável para todas as crianças" ( p. 19).

Segundo Valadão (2003), a perspectiva na discussão da promoção de saúde é construir estratégias de trabalho baseadas nos padrões de vulnerabilidade; entretanto, para diminuir essa vulnerabilidade, é 
necessário planejar ações em três níveis complementares: 1) no nível pessoal, em que devem ser contempladas as necessidades e singularidades de cada indivíduo; 2) no nível social, com vista a transformar as condições que geram as doenças; e 3) no nível das instituições, as quais devem desenvolver programas coerentes. A vulnerabilidade está associada aos comportamentos pessoais que criam a oportunidade de emergirem problemas de saúde. Estes comportamentos dependem do grau e da qualidade das informações de que os indivíduos disponham sobre o problema, da capacidade de elaborar essas informações e incorporá-las no seu repertório cotidiano e de transformar ideias em práticas. A vulnerabilidade também está associada a componentes sociais, como o grau de escolaridade, a disponibilidade de recursos materiais, o poder de influenciar decisões políticas e enfrentar barreiras culturais, o grau de liberdade de pensamento e expressão, a possibilidade de tomar decisões e de agir num determinado contexto social. Quanto às instituições, a vulnerabilidade está associada ao compromisso das autoridades com a superação do problema em questão, a implantação de ações e serviços eficientes e acessíveis, a ação integrada e a continuidade dos programas.

De acordo com Gonçalves (2003), a presença da Psicologia nas políticas públicas se efetivou por meio da educação e da saúde e se caracteriza por ações preventivas e de correção, tendo como referência a lógica da patologia, pautada numa naturalização dos fenômenos psicológicos. De acordo com Cruz et al. (2005), essa ação legitimou a exclusão por meio de uma terapêutica com foco no indivíduo desviante, sem considerar aspectos sociais desse desvio. Desta forma, a Psicologia, no Brasil, nasce em um Estado autoritário e cumpre um papel de impor uma modernização industrial com a garantia do mínimo necessário, muito diferentemente de outros países, cujo processo de industrialização se seu com políticas do Estado de Bem-Estar Social já efetivadas. Foi a partir da Psicologia Comunitária que se construíram novos conhecimentos e práticas mais coerentes com a realidade brasileira, visando à emancipação dos indivíduos, ao considerá-los dentro do contexto social no qual estão inseridos e constituídos historicamente (Gonçalves, 2003).

\section{MÉTODO}

O presente estudo realizou-se a partir de um estágio curricular em Psicologia Jurídica no curso de Psicologia da Universidade Presbiteriana Mackenzie em São Paulo. As atividades do estágio foram: observações do cotidiano de um Conselho Tutelar (CT) de São Paulo, plantão de Psicologia Jurídica junto à população, discussão dos casos atendidos com conselheiros e a coordenação de um grupo de adolescentes encaminhados por uma escola da região. O estágio teve a duração de cerca de dez meses, no ano de 2007, com visitas semanais de 4 horas.

\section{RESULTADOS E DISCUSSÃO}

O CT onde se realizou o estágio atua desde 2002 e era responsável pelo atendimento de uma área com 600.000 habitantes, da Zona Sul da cidade de São Paulo. Localizava-se no prédio da subprefeitura da região e seu espaço físico compreendia um conjunto de quatro ambientes, onde atuavam cinco conselheiros. A rede de serviços e proteção social com que o CT podia contar era escassa, ou seja, na região existiam poucos projetos socioeducativos, culturais, ou mesmo possibilidades de vagas em equipamentos de educação e saúde direcionados às famílias, crianças e adolescentes.

A queixa principal da população era a falta de vaga em creches ou escolas. De acordo com um levantamento dos atendimentos realizados em 2005 pelos conselheiros, verificou-se que, dos 1971 casos atendidos, aproximadamente $48,7 \%$ estavam relacionados à educação, e destes, $50,6 \%$ relacionavam-se a pedidos de vaga em creches; $31,6 \%$ dos casos atendidos referiam-se a problemas familiares, como conflito entre os membros, problemas de saúde, comportamento e outros; e 19,7\% referiam-se a casos de violência, em sua grande maioria à maus-tratos e negligência. Pôde-se também observar que por trás dos pedidos de vagas existiam muitos outros problemas, como conflitos familiares e situações de violência. $\mathrm{Na}$ maioria dos casos atendidos, pôde-se notar alguma violação dos direitos básicos, como moradia, educação, saúde, e alimentação, o que Sales (2007) nomeia de cultura de violência, ligada ao processo de formação da sociedade brasileira e à nossa rarefeita cidadania, principalmente nas classes trabalhadoras, em que o Estado só garante direitos em situações-limite - isto quando o faz. Essa violência sofrida, pela não garantia de seus mínimos direitos, faz com que a violência se torne uma vivência cotidiana nas periferias dos grandes centros urbanos.

Cruz et al. (2005) afirmam que apenas os pobres chegam ao $\mathrm{CT}$, vítimas de maus-tratos e negligência familiar, embora este equipamento social seja dirigido a todas as crianças; e conquanto o ECA defenda que a 
criança não pode ser retirada de sua família por motivos socioeconômicos, a pobreza ainda determina, de forma subliminar, os motivos para abrigamento. A questão que merece reflexão é quem está sendo negligente: a família ou o Estado, que não assegura os direitos dos cidadãos? Observaram-se famílias nas quais os adultos saíam para trabalhar e as crianças ficavam sem cuidados, o que facilmente era enquadrado como negligência, e não como deficiência do Estado em proporcionar equipamentos socioeducativos para a população. Pôde-se perceber que o CT funcionava como porta de entrada de denúncias dessa violência silenciosa do Estado, de violação de direitos básicos, em todas as áreas: hospitais, postos de saúde, escolas, creches, instituições diversas que não davam conta de atender à demanda, além das situações de miséria e desamparo vividas por várias famílias.

Costa et al. (2007), em uma pesquisa com dois CTs na Bahia, constataram que a maioria dos atendimentos relacionados a situações de violência referiam-se a negligência e maus-tratos, o que também foi observado no CT em que se realizou o estágio, o que reafirma a necessidade de uma reflexão maior sobre a garantia de direitos e a violência intrafamiliar.

Os casos atendidos no CT em 2007 apresentaram as mesmas características do levantamento realizado em 2005: a predominância de solicitações de vagas em escolas e creches, conflitos familiares envolvendo adolescentes ou crianças com dificuldades diversas na escola, além de situações de violência intrafamiliar. Esses casos precisavam ser encaminhados, mas para isso era preciso uma rede de proteção social, com serviços destinados às famílias, crianças e adolescentes. Também nesse momento encontrou-se a ausência do Estado, que foi violador, na medida em que não garantiu os direitos básicos, e continua a sêlo, ao não oferecer uma rede de proteção social.

Além da falta de políticas públicas em relação aos adolescentes e crianças, existe uma falta ainda maior de políticas públicas voltadas às famílias. Pôde-se perceber, nos atendimentos efetuados, que as famílias eram culpabilizadas pelas violações de direitos da criança ou adolescente e se fragilizavam ainda mais quando, ao procurar o CT, eram enquadradas como negligentes, pela falta de rede social, além de se sentirem fracassadas quando comparadas ao ideal social de família burguesa (Gomes, 1992). Segundo Gomes (1992), muitas transformações sociais ocorreram nas últimas décadas e influenciaram a estrutura familiar. As mulheres, que anteriormente se dedicavam à educação dos filhos e cuidavam dos afazeres domésticos, agora participam ativamente do orçamento familiar. Em camadas economicamente menos favorecidas uma rede de apoio auxilia no cuidado, porém essa rede não existe. Como observado no CT, em sua maioria as mulheres são mães adolescentes, provedoras da casa e, muitas vezes, as únicas adultas que cuidam das crianças. Não obstante, essas transformações ainda não foram plenamente compreendidas e ainda existe um ideal social de família "estruturada" permeando as expectativas das próprias famílias, dos técnicos de diversos equipamentos sociais e dos conselheiros, o que concorre para a culpabilização das famílias que procuram o CT.

Foi grande o número de pais que procuraram o conselho em busca de orientações com relação aos filhos, geralmente adolescentes que não queriam ir à escola ou que fugiam de casa e passavam a usar drogas. A fuga constante dos adolescentes em busca de "liberdade" é algo que precisa ser compreendido. Ao ir para as ruas, o adolescente deixa de ser um anônimo e passar a ter uma identidade; entretanto, ao sair de casa para tornar-se sujeito, ele encontra a negação de sua condição de sujeito, por exemplo, como "menino de rua" (Calil, 2003). De acordo com Bucher (citado por Calil, 2003), o consumo de drogas também se encontra nessa lógica perversa da regulação social que destina aos usuários o espaço da exclusão, onde eles têm a droga como companhia. Os filhos que saem de casa em busca da "liberdade", também estão uma busca de visibilidade. Sales (2007) ressalta aspectos da (in)visibilidade perversa, afirmando que os adolescentes querem ser vistos, ter reconhecimento e prestígio social; compreendem o poder e a força da imagem que os associa à rebeldia e tiram partido dela; e, na impossibilidade de gratificação imediata em termos de objetos de consumo e lazer estimulados pela cultura de massas, muitos jovens aderem aos apelos da criminalidade. Calil (2003) enfatiza que é a partir dessa lógica perversa da relação inclusão - exclusão que permeia a sociedade capitalista que o jovem torna-se incluído após assumir a sua exclusão.

Nos atendimentos aos adolescentes, procurou-se estabelecer uma relação de proximidade, escuta e acolhimento. Rocha (2006) considera que a escuta e a consideração daquilo que os jovens têm a dizer a respeito de si próprios e do mundo apontam para a construção de projetos, bem como de sentidos individuais e coletivos em relação ao seu lugar na sociedade, às suas relações, às suas aspirações. A intervenção junto aos adolescentes foi, neste sentido, de ruptura com uma posição autoritária, buscando-se tecer com eles um laço de pertença com o grupo e, 
posteriormente, com a sociedade, por meio de um projeto de vida.

Pôde-se observar nos plantões psicojurídicos que a oferta de um espaço de acolhimento e escuta do sofrimento da comunidade pode fazer desta instituição, de fato, uma instituição de proteção social. Desta forma, em uma rede de proteção se faz necessário um orientador com uma boa formação humana e capaz de compreender os emaranhados da situação de abandono e as situações de miséria (Souza Neto, 2006). Souza Neto (2006) considera o CT como um espaço de desenvolvimento de cidadania plena, de autonomia; um lugar no qual as pessoas possam falar e ser escutadas, olhar para si mesmas e recuperar a coragem de lutar pelos seus direitos, sendo orientadas para isto. É possível caminhar na direção da construção do desenvolvimento da autonomia das pessoas que usam o serviço dos equipamentos sociais como fator de transformação tanto da comunidade quanto da sociedade em geral; porém o desenvolvimento de potencialidades para que a autonomia apareça é bastante complexo e envolve transformação e esclarecimento, portanto não pode ser algo isolado.

Nesse sentido, o CT pode ser um equipamento social de proteção de direitos ou de legitimação da exclusão social pela manutenção da violação de direitos. Ele funciona como um grande catalisador de diversas situações de vulnerabilidade, e pode se tornar referência para a comunidade, como aliado na garantia de direitos das crianças e adolescentes. A Psicologia pode e deve se inserir nessa instituição, de forma a contribuir para a promoção de saúde da população, buscando a garantia do desenvolvimento pleno da criança e do adolescente e deixando o padrão hegemônico de atuação centrada no modelo médico, clínico e individual, que acaba desconsiderando os aspectos estruturais da sociedade (Gonçalves, 2003).

A ideia de promoção de saúde, no que concerne às políticas públicas voltadas a essa população, consiste em propiciar aos sujeitos a atenção integral, que pode diminuir a vulnerabilidade destas pessoas nos três níveis referenciados por Valadão (2003): pessoal, social e institucional. Com esta perspectiva, o sujeito pode compreender as causas de seu sofrimento e instrumentalizar-se de forma a poder transformar a sua realidade e adquirir autonomia (Valadão, 2003).

\section{CONSIDERAÇÕES FINAIS}

Pôde-se observar que o Conselho Tutelar funciona como uma porta de entrada de todas as dificuldades da comunidade e das diversas situações de vulnerabilidade. Para que o CT possa exercer sua função de garantia de direitos, ele precisa ter como apoio uma rede de serviços à população, e para isso acontecer, é preciso um Estado que garanta direitos de todos os cidadãos.

O Conselho Tutelar deve ser um aliado da população e deve se posicionar ativamente; deve lutar pela implantação de uma efetiva rede de proteção à criança e ao adolescente e pela defesa dos direitos básicos da população. Desta forma, o CT pode ter uma função de orientação da população, de forma a instrumentalizá-la para transformar sua realidade, adquirindo autonomia e cidadania plena.

Seria importante que o conselheiro pudesse contar com o apoio de profissionais de outras áreas, com os quais pudesse discutir os casos e refletir melhor sobre as medidas mais adequadas. A Psicologia teria contribuições significativas a oferecer, e deve estar presente em situações em que os direitos sejam violados, para ativamente participar dessa conquista social.

\section{REFERÊNCIAS}

Araujo, M. F.; Matiolli, O. C. (2004). Gênero e Violência: arte e Ciência, Rio de Janeiro:Arte Ciência.

Brasil. Presidência da República. (1990). Lei 8.069 de 13 de julho de 1990. Dispóe sobre o Estatuto da Criança e do Adolescente e dá outras providências. Brasilia, DF: Diário Oficial da União de 16 de julho de 1990.

Calil, M. I. (2003). De menino de rua a adolescente: análise sócio-histórica de um processo de ressignificação do sujeito. In S. Ozella. (Org.), Adolescências Construídas: a visão da psicologia sócio-histórica. São Paulo: Cortez.

Costa, M. C. O., Carvalho, R. C., Santa Bárbara, J. F. R., Santos, C. A. S. T., Gomes, W. A. \& Sousa, H. L. (2007). O perfil da violência contra crianças e adolescentes, segundo registros de Conselhos Tutelares: vítimas, agressores e manifestações de violência. Ciência e saúde coletiva, 12(5), 1129-1141. Recuperado em 20 agost,o de 2007, de http://www.scielo.br/pdf/csc/v12n5/04.pdf.

Cruz, L., Hillesheim, B.\& Guareschi, N. M. F. (2005). Infância e políticas públicas: um olhar sobre as práticas. Psicologia \& Sociedade, 17(3), 42-49. Recuperado em 02 setembro, de 2007, de http://www.scielo.br/pdf/psoc/v17n3/a06v17n3.pdf.

Gomes, H. S. R. (1992) Trabalhando com famílias. Caderno de Ação, n. 1. São Paulo: Cortez.

Gonçalves, M. G. (2003) Psicologia Sócio-Histórica e Políticas Públicas: a dimensão subjetiva de fenômenos sociais. Tese de Doutorado não-publicada, Programa de estudos Pós-Graduados em Psicologia Social, Pontifícia Universidade Católica de São Paulo, São Paulo.

Rizzini, I., G., Barker, G.\& Cassaniga, N. (2000) Criança não é risco, é oportunidade: fortalecendo as bases de apoio familiares e comunitárias para crianças e 
adolescentes. Rio de Janeiro: EDUSU: Instituto Promundo. Recuperado em 18 março, de 2009, de www.promundo.org.br.

Rocha, M. C. (2006) Juventude: apostando no presente. Imaginario. [online]. 12(12). Recuperado em 20 setembro, de 2007 em www.pepsic.bvs-psi.org.br.

Sales, M. A. (2007). (In) Visibilidade perversa: adolescentes infratores como metáfora da violência. São Paulo: Cortez.

Souza Neto, J. C. (2006) Apontamentos para reflexão sobre concepções das práticas de atendimento à criança e ao Adolescente. In J. C. Souza Neto \& M. L. B. P. Nascimento (Org.). Infância: Violência, Instituições e Políticas Públicas. São Paulo: Expressão e Arte.
Valadão, M. M. (2003) A saúde nas políticas públicas: juventude em pauta! In, M. V. Freitas \& F. C. Papa (Org.). Políticas Públicas: juventude em pauta. São Paulo: Cortez: Ação Educativa Assessoria, Pesquisa e Informação: Fundação Friedrich Ebert.
Endereço para correspondência:
Vania Conselheiro Sequeira. Rua da Consolação 896, Consolação, CEP 01302 907, São PauloSP, Brasil.E-mail: vania.sequeira@mackenzie.br. 